\title{
Use of Phase-Contrast MRA to Assess Intracranial Venous Sinus Resistance to Drainage in Healthy Individuals
}

\author{
(D) Fall, (D) G. Pagé, (D). Bettoni, (D) R. Bouzerar, and (D) O. Balédent
}

\begin{abstract}
BACKGROUND AND PURPOSE: Resistance to blood flow in the cerebral drainage system may affect cerebral hemodynamics. The objective of the present study was to use phase-contrast MRA to quantify resistance to drainage of blood across branches of the venous sinus tree and to determine whether the resistance to drainage values correlated with internal jugular vein outflows.
\end{abstract}

MATERIALS AND METHODS: We performed whole-head phase-contrast MRA and 2D phase-contrast MR imaging in 31 healthy volunteers. Vascular segmentation was applied to the angiograms, and the internal jugular vein velocities were quantified from the flow images. Resistance to drainage across branches of the venous sinus tree was calculated from the segmented angiograms, by using the Poiseuille equation for laminar flow. Correlations between the values of resistance to drainage and internal jugular vein outflow measurements were assessed by using the Spearman $\rho$.

RESULTS: The overall mean resistance to drainage of the venous sinus tree was $24 \pm 7 \mathrm{~Pa} \mathrm{~s} / \mathrm{cm}^{3}$. The mean resistance to drainage of the right side of the venous sinus tree was $42 \%$ lower than that of the left side $(P<.001)$. There were negative correlations between the values of resistance to drainage and internal jugular vein outflows on both the left side of the venous sinus tree $(R=-0.551, P=.002)$ and the right side $(R=-0.662, P<.001)$.

CONCLUSIONS: Phase-contrast MRA is a noninvasive means of calculating the resistance to drainage of blood across the venous sinus tree. Our approach for resistance to drainage quantification may be of value in understanding alterations in the cerebral venous sinus drainage system.

ABBREVIATIONS: $\mathrm{Al}$ = asymmetry index; IJV = internal jugular vein; PC-MRA = phase-contrast MR angiography; Rd = resistance to drainage

$\mathbf{T}$ he cerebral venous sinus system is characterized by anatomic variations ${ }^{1}$ associated with marked interindividual variability in blood drainage patterns. ${ }^{2}$ The venous compartment is generally compliant, whereas the walls of the sinuses tend to be rigid. In comparison with the intracranial arterial system, the venous sinus system has received less attention in the imaging-based evaluation of cerebrovascular diseases in clinical research, possibly because the pathologies that affect the intracranial venous sinus system are less common than those affecting the arterial system and often present a broad spectrum of clinical manifestations. ${ }^{3}$ However,

Received April 20, 2016; accepted after revision September 11.

From the BioFlow Image Laboratory (S.F., G.P., O.B.), University of Picardy Jules Verne, Amiens, France; Maxillofacial Department (J.B.) and Medical Image Processing Department (R.B., O.B.), University Hospital of Picardy, Amiens, France; and ICube-IRMA (S.F.), Strasbourg University, Illkirch, France.

The research was funded in part by the French National Research Agency (grant ANR-12-MONU-0010).

Please address correspondence to Sidy Fall, MD, BioFlow Image, University of Picardy Jules Verne, Chemin du Thil, F-80000, Amiens, France; e-mail: fall.sidy@chu-amiens.fr

http://dx.doi.org/10.3174/ajnr.A5013 alterations in cerebral hemodynamics are known to be associated with abnormal drainage in the cerebral venous sinus system. For example, impaired intracranial drainage is widely cited as one of the prime causes in idiopathic intracranial hypertension, ${ }^{4-7}$ intracranial dural arteriovenous fistula malformation, ${ }^{8}$ communicating and noncommunicating hydrocephalus, ${ }^{9,10}$ and multiple sclerosis. ${ }^{11}$ Nevertheless, a suspected case of venous stenosis must be assessed with caution ${ }^{12}$ because misinterpretation can lead to a nonindicated operation (with all its associated non-negligible risks). This point is clearly illustrated by the debate over the involvement of jugular venous stenosis in the pathogenesis of multiple sclerosis. In multiple sclerosis, it has been shown that percutaneous transluminal angioplasty of extracranial veins with suspected alterations is ineffective, may exacerbate underlying disease activity, and can lead to serious complications. ${ }^{13}$

In clinical practice, intraluminal vessel defects and/or pathologic flow velocities of the intracranial drainage system are usually evaluated by using contrast-enhanced or unenhanced MR imaging, ${ }^{5} \mathrm{CTA},{ }^{14} \mathrm{DSA},{ }^{15}$ or transcranial Doppler sonography. ${ }^{16} \mathrm{Al}-$ 
though unenhanced vascular imaging techniques are less sensitive than contrast-enhanced techniques, they may be of value for an initial evaluation of the venous system in neonates or in patients who are allergic to contrast agents or have kidney dysfunction. Unenhanced 3D phase-contrast MRA (PC-MRA) offers several advantages: It is relatively rapid, is often appropriate for patient follow-up, and is associated with a lower complication rate. ${ }^{17,18}$ The results of patient evaluations usually show that a narrower luminal cross-section can produce higher flow resistance and therefore a decrease in flow and an increase in pressure-at least in the region adjacent (proximal) to the lesion. Moreover, venous sinus manometry has shown an elevated sagittal sinus pressure and a significant drop in transverse sinus pressure in patients with idiopathic intracranial hypertension. ${ }^{19}$ Other researchers have shown that most patients with idiopathic intracranial hypertension have normal blood flow in the superior sagittal sinus. ${ }^{7}$

The mechanisms linking the cerebral venous outflow rate to intracranial pressure have not been characterized, to our knowledge. However, it is possible that structural factors (such as an increase in the resistance to drainage [Rd] of blood across the branches of the venous sinus pathways) may impact intracranial venous outflow, as has been demonstrated in patients with venous outflow obstruction (in whom an elevated venous back pressure resulted in elevated venous resistance ${ }^{20}$ ). It is generally assumed that the pressure drop for driving axial flow across a tube increases with the flow resistance. Thus, an increase in venous sinus flow resistance would require an increase in upstream flow pressure for a constant volume flow through this drainage system to be maintained. Hence, the cumulative effects of the Rd across segments of the venous sinus pathways may have a role in cerebral hydrodynamics in general and in intracranial pressure and cerebral compliance in particular.

While the association between intracranial hydrodynamics and the geometric characteristics of the venous sinus system appears to be strong, we are not aware of any quantitative data on the resistance to blood flow in the cerebral drainage system. The objective of the present study was therefore to calculate the Rd of blood across the major dural sinuses and internal jugular veins (IJVs) in healthy volunteers by using phase-contrast MR angiography. We used the well-established Poiseuille equation for laminar flow to calculate the Rd from the PC-MRA data. Furthermore, we explored the relationship between the values of $\mathrm{Rd}$ and the IJV flows measured by cine phase-contrast MR imaging.

\section{MATERIALS AND METHODS Participants}

Twenty-nine healthy volunteers (mean age, $26.7 \pm 5.5$ years; 18 women and 11 men) were recruited. None had a history of neurovascular disease. The study was approved by the regional investigational review board, and all participants gave their written, informed consent.

\section{Image Acquisition}

Images were acquired with a 3T MR imaging system (dStream; Philips Healthcare, Best, the Netherlands) equipped with a 32channel digital head coil, by using a 3D PC-MRA sequence. This sequence exploits the property whereby spins that move through

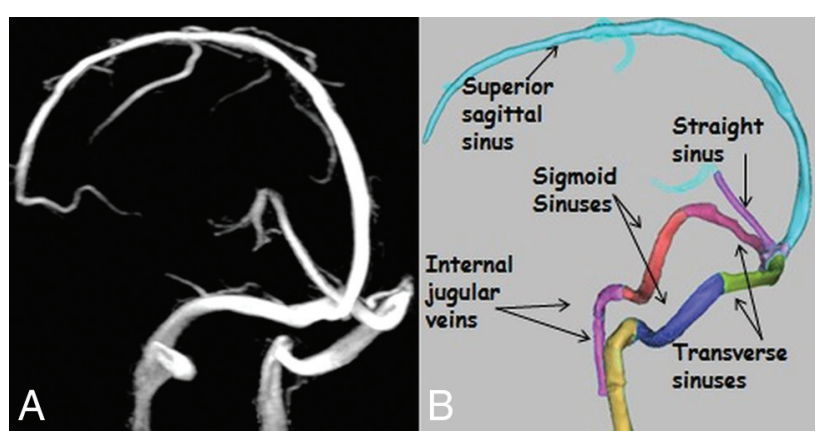

FIG 1. Representative examples of maps of the venous sinus tree. $A$, Maximum-intensity projection of a 3D PC-MRA source image. $B$, The venous sinus tree segmentation was produced by Mimics software.

a bipolar gradient field accumulate a phase difference, whereas static spins do not. The bipolar flow-encoding gradients can be applied simultaneously along 3 axes to measure the corresponding flow sensitivities. The sensitivity of the PC-MRA technique can be controlled by using a parameter sequence commonly referred to as "velocity-encoding." More details of this technique have been presented by Dumoulin et al. ${ }^{21}$

PC-MRA was performed in the sagittal plane (covering the whole cerebral venous system and some of the IJVs, up to the C3-C4 cervical vertebrae) by using the following parameters: FOV $=220 \times 220$ $\mathrm{mm}^{2}$; number of sections $=320$; effective spatial resolution $=0.7 \times$ $0.7 \mathrm{~mm}^{2}$; flip angle $=12^{\circ}$; velocity-encoding $=30 \mathrm{~cm} / \mathrm{s} ; \mathrm{TR}=5.5$ $\mathrm{ms}$; TE $=3 \mathrm{~ms}$; acquisition time $=6$ minutes. Next, 2D PC-MR images were acquired perpendicular to the IJVs near the $\mathrm{C} 2$ and $\mathrm{C} 3$ vertebrae, by using a gated cine PC-MR imaging pulse sequence. The main scan parameters were as follows: FOV $=120 \times 120 \mathrm{~mm}^{2}$; resulting spatial resolution $=0.5 \times 0.5 \mathrm{~mm}^{2}$; section thickness $=2$ $\mathrm{mm} ; \mathrm{TR} / \mathrm{TE}=14 / 8 \mathrm{~ms} ;$ flip angle $=30^{\circ}$; velocity-encoding $=80$ $\mathrm{cm} / \mathrm{s}$; cardiac phases $=16$. The acquisition times ranged from 1.2 to 1.8 minutes, depending on the heart rate.

\section{Image Processing}

The PC-MRA datasets were imported into Mimics software (Materialise, Leuven, Belgium) for 3D, semiautomated segmentation of the cerebral venous sinus tree (represented as the superior sagittal, straight, transverse, and sigmoid sinuses and the IJVs). Threshold-based segmentation was used to extract the venous sinus tree from each angiogram. To this end, the section passing as close as possible to the mesial plane of the straight sinus was selected, and an intensity profile was obtained along a line perpendicular to the sinus. A suitable intensity threshold was then determined from this profile $(17 \%-23 \%$ of its maximum intensity, depending on the image quality for each participant). All voxels with signal intensities below this threshold value were masked. Figure 1 shows a typical segmentation of the venous sinus tree. The final segmented geometry was converted into a Standard Tessellation Language file format. The Standard Tessellation Language file was then imported into the Vascular Modeling Toolkit software (www.vmtk.org) for quantification of the length, crosssectional area, and associated radius at $10-\mathrm{mm}$ intervals along each vessel segment. To avoid possible bias due to anatomic variations, we excluded the anterior portion of the superior sagittal sinus from the calculation. 
For the flow images, IJV flow velocities at the C2-C3 cervical vertebrae were quantified throughout the cardiac cycle by using freely available, semiautomatic software (Bio Flow image; http://www.tidam.fr). Details of the flow measurement have been described previously. ${ }^{22}$

\section{Calculation of Resistance and Flows}

The Rd of each 10-mm segment was calculated by applying the Poiseuille equation for laminar flow:

$$
R d=\frac{8 \mu L}{\pi r_{\mathrm{h}}^{4}},
$$

where $L(10 \mathrm{~mm})$ and $r_{\mathrm{h}}$ are the length and the radius of the segment, respectively, and $\mu$ is the viscosity of the blood. The total Rd for a selected part of the venous sinus tree was calculated by summing the Rd for all the component 10 -mm segments.

The left- or right-sided Rd for the venous sinus tree was calculated by summing the Rd values for the transverse sinus, sigmoid sinus, and IJV on each side of the head. An overall Rd for the venous sinus tree was also calculated by analogy with an electric circuit (Fig 2). Details of the mathematic equation for calculation of the overall Rd are presented in the Appendix.

The flows in each IJV were also added to obtain the total IJV flow. Figure 3 shows the change in mean flow in the IJVs over the cardiac cycle in 1 participant.

\section{Statistical Analysis}

Statistical analysis was performed with $\mathrm{R}$ statistical and computing software (Version 3.2.3; http://www.r-project.org/). A Wilcoxon matched-pairs test was used to probe for differences between the left and right sides of the venous sinus tree. Correlations

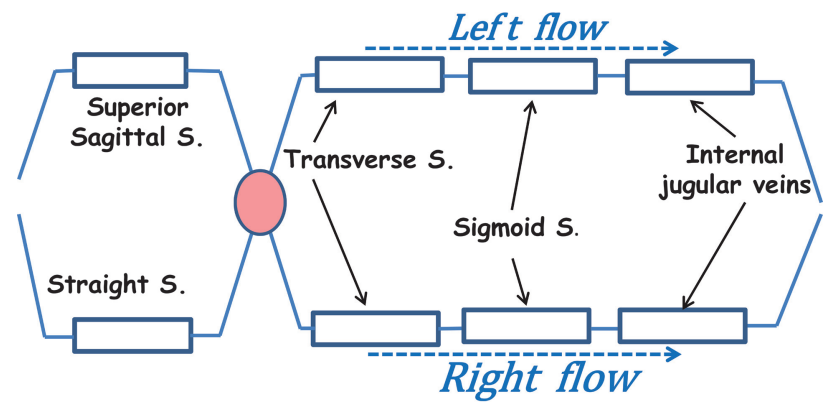

FIG 2. Schematic representation of the modeled venous system. S. indicates sinus.
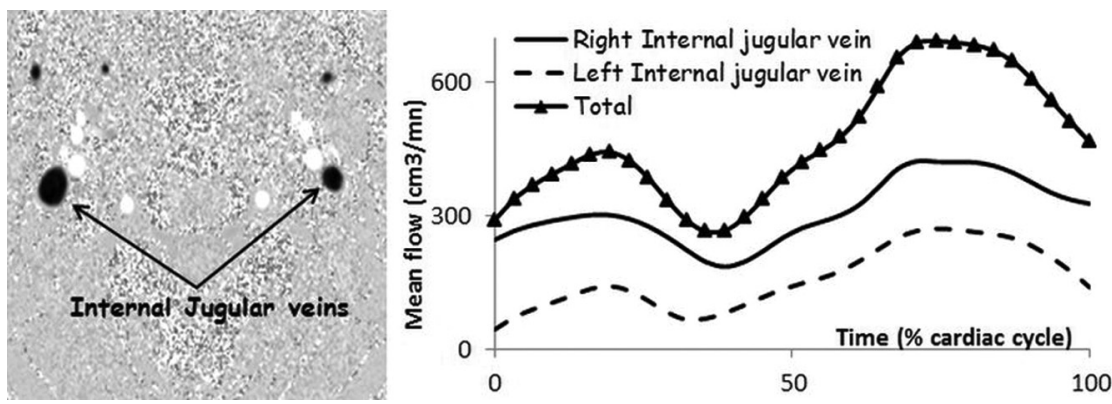

FIG 3. An example of phase-contrast MR imaging showing the $2 \mathrm{IJV}$ (at the C2-C 3 vertebrae) and typical flow curves over the cardiac cycle in 1 participant. The curve marked with triangles shows the total mean flow through the left and right IJVs. between the values of Rd and blood flow measurements of the IJVs were assessed by using the Spearman $\rho$. The threshold for statistical significance was set at $P<.05$.

We calculated the correlations between the values of $\mathrm{Rd}$ and IJV flow measurements for each side of the venous tree and between the overall Rd for the venous sinus tree and the total IJV flow measurements. We also looked at whether there was an association between sidedness in flow and sidedness in Rd in the venous sinus tree. To this end, we calculated 2 asymmetry indices (AIs) for each participant:

The resistance AI, reflecting asymmetry resistance, was the following:

Resistance AI = (left-sided Rd

- right-sided Rd) / (left-sided Rd + right-sided Rd).

The flow AI, reflecting IJV flow dominance, was the following:

Flow AI = (left IJV flow - right IJV flow) / (left IJV flow

+ right IJV flow).

The AIs obtained with these 2 equations ranged from -1 (strong right dominance) to +1 (strong left dominance). The strength of the sidedness (for flow or resistance) was categorized as $+0.2<\mathrm{AI}<+1$ (left-sided dominance), $-0.2<\mathrm{AI}<-1$ (right-sided dominance), and $-0.2<\mathrm{AI}<+0.2$ (codominance).

The correlation between the flow AIs and resistance AIs were also evaluated.

\section{RESULTS}

The mean values of Rd for each vessel segment and for the venous sinus tree as a whole are summarized in the Table. Significant sidedness was observed for the mean of Rd (left side versus right side, $42.1 \pm 17$ versus $\left.18.4 \pm 10 \mathrm{~Pa} \mathrm{~s} / \mathrm{cm}^{3} ; P<.001\right)$ and the measured flows (left side versus right side, $250 \pm 108$ versus $349 \pm$ $124 \mathrm{~cm}^{3} / \mathrm{min} ; P=.02$ ). Left-dominant, right-dominant, and codominant flow was observed in, respectively, $17 \%, 48 \%$, and $35 \%$ of the participants.

Scatterplots of the associations between the values of $\mathrm{Rd}$ and flow measurements are shown in Fig 4. There were significant negative correlations between the values of $\mathrm{Rd}$ and the flow measurements on both the left side of the venous sinus tree $(R=$ $-0.551, P=.002)$ and the right side $(R=-0.662, P<.001)$. When we considered associations between flow dominance and resistance dominance, there was a strong negative correlation between the flow AIs and the resistance AIs $(R=-0.792$, $P<.001)$ as illustrated by a scatterplot (Fig 5). There was no significant correlation between total resistance and total venous outflow $(R=-0.359, P=.06)$.

\section{DISCUSSION}

It has been suggested that cerebral venous sinus insufficiency is a major factor in certain neurovascular diseases. ${ }^{4,5,8-10,23}$ Apart from evaluations of anatomic abnormalities and the quantification of 
narrowed vessels and abnormal flow/pressure patterns, ${ }^{24,25}$ little is known about resistance to blood flow in the cerebral venous sinus drainage system. Here, we describe a novel approach for calculating the Rd through the cerebral venous tree; it is based on the application of the Poiseuille equation for laminar flow to data from phase-contrast MRA, a highly sensitive technique for noninvasive imaging of the cerebral venous sinus system. ${ }^{26}$

In the present study, we hypothesized that turbulent flow conditions occur very infrequently. To confirm this hypothesis, we calculated the Reynolds number $(R e)$ for the study participants' superior sagittal sinus and IJVs according to the following equation: $R e=\rho V D / \mu$, where $V$ is the maximum velocity, $D$ is the diameter of the luminal cross-section, $\rho$ is the attenuation of blood, and $\mu$ is the viscosity of blood. The highest Reynolds number that we obtained was 392, well below the value of 2000 at which turbulent flow conditions can be expected. ${ }^{27}$

The blood flows through the IJVs measured in our study agree with the literature data. ${ }^{28} \mathrm{We}$ also observed relatively high interindividual variations in both the calculated $\mathrm{Rd}$ and outflows. These flow variations have been reported by others ${ }^{2}$ and may reflect anatomic variants rather than changes in physiologic conditions. ${ }^{11}$ The total venous flow appeared to be correlated with the overall Rd of the venous sinus tree, though the relationship did not achieve statistical significance. One possible explanation is that our representation of the very complex venous sinus pathway was oversimplified; some branches of the venous drainage network were not taken into account in our calculation of the overall resistance. For example, the straight sinus drains the deep venous

Values of the mean Rd of blood in the study population of healthy adults

\begin{tabular}{lc}
\hline & Mean $\mathbf{R d}\left(\mathbf{P a ~ s} / \mathrm{cm}^{3}\right)$ \\
\hline Superior sagittal sinus & $20.1 \pm 6$ \\
Straight sinus & $41.2 \pm 21$ \\
Transverse sinus & \\
$\quad$ Left & $21.5 \pm 14$ \\
$\quad$ Right & $8.5 \pm 5$ \\
Sigmoid sinus & \\
$\quad$ Left & $11.6 \pm 6$ \\
$\quad$ Right & $4.8 \pm 3$ \\
Internal jugular vein & \\
$\quad$ Left & $8.5 \pm 7$ \\
$\quad$ Right & $5.1 \pm 4$ \\
Overall Rd & $23.8 \pm 7$ \\
\hline
\end{tabular}

system through the inferior sagittal sinus and the vein of Galen. ${ }^{29}$ The transverse sinus also receives the superior petrosal sinuses and the veins of Labbé, which drain blood from the temporooccipital cortex. Moreover, the drainage pathways include the emissary veins, vertebral veins, and pterygoid plexus; this network may also explain the lack of a statistically significant correlation between the values of the overall Rd and the total IJV flow measurements. We chose to limit our measurements to the major dural sinuses, in view of the high interindividual variations in the venous sinus system. ${ }^{30}$

Another unique feature of the cerebral venous drainage system is its dependence on posture. In the upright position, the IJVs tend to collapse and thus prompt a concomitant rise in flow in the vertebral veins ${ }^{31}$; in the supine position, they are the main drainage pathways for the cerebral outflow. Our participants were imaged in the supine position, which minimized the impact of position on both flow and Rd measurements of the IJVs.

The present findings and previous reports ${ }^{2,32}$ show that venous drainage is dominated by the right outflow, reflecting the asymmetry in the resistance between the left and right sides of the venous sinus pathway. Furthermore, the relationship between resistance and flow was highlighted by our observation of a strong, inverse correlation between the resistance AIs and the flow AIs. The presence of an inverse association may indicate a lateralization effect, whereby one side compensates for the other. ${ }^{2,28}$ It may also underline the importance of flow resistance in the regulation of cerebral blood outflow. Although our results are preliminary, they suggest that the cumulative effects of resistance to flow along vessel segments may have repercussions on the intracranial hydrodynamics, insofar as cerebral blood outflow may be influenced by the venous sinus resistance to flow. It is also possible that an elevated Rd across the cerebral sinus pathways contributes to the elevation of blood pressure on the venous side of the cerebral vascular tree. An elevation in venous pressure makes the cortical veins stiffer and induces a decrease in craniospinal compliance. ${ }^{33}$ Furthermore, several researchers have emphasized the relevance of the venous sinus drainage system in hydrocephalus. ${ }^{9,10}$ One hypothesis is that elevated pressure in the venous system may lead to alterations in CSF resorption through the arachnoid granulations. Moreover, other researchers have suggested that reduced cortical vein compliance and reduced superior sagittal sinus flow in normal-pressure hydrocephalus indicate the presence of a sig-
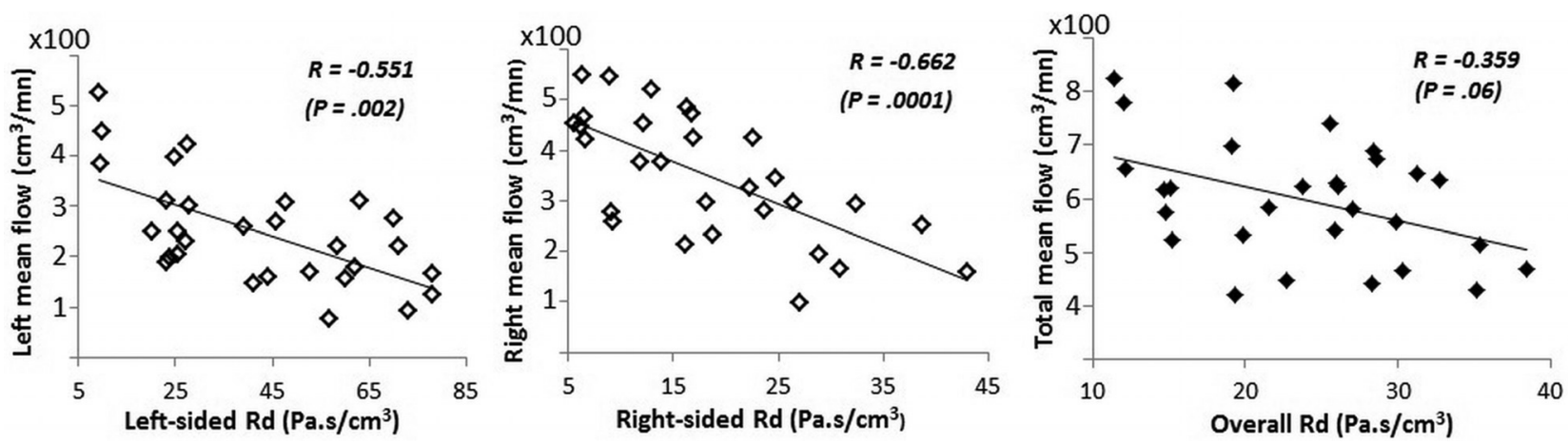

FIG 4. The relationship between mean flow and calculated Rd on the left (left panel) and right (middle panel) sides of the venous sinus tree. The vessels of the left and right sides, respectively, comprise the 3 left or right vessel segments (the transverse sinus, sigmoid sinus, and IJV). The right panel shows the relationship between total mean flow and the overall Rd. 


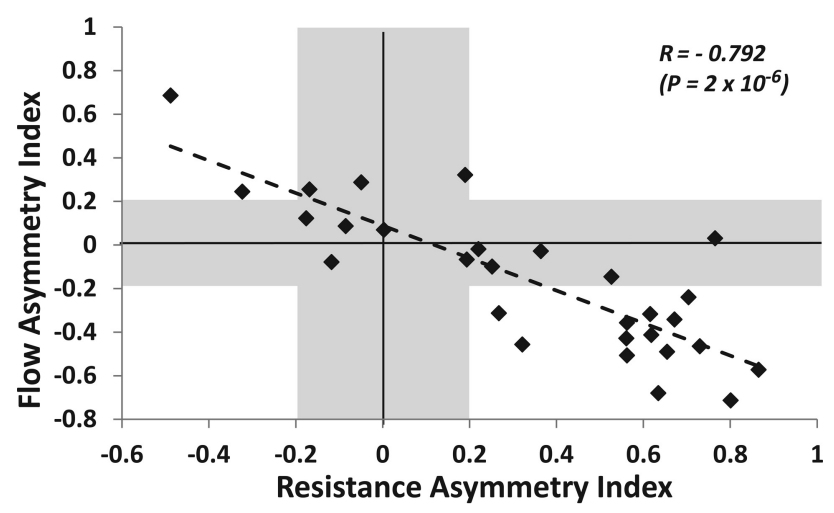

FIG 5. Flow Als plotted against resistance Als. Diamonds located below the horizontal gray band (AI $<-0.2$ ) reflect right-sided flows, and those above the horizontal gray band $(\mathrm{Al}>+0.2)$ reflect leftsided flows. Diamonds located to the left of the vertical gray band $(\mathrm{Al}<-0.2)$ reflect right-sided resistance, and those on the right of the vertical gray band $(\mathrm{Al}>+0.2)$ reflect left-sided resistance.

nificant elevation in the resistance to flow through these vessels. $^{34,35}$ The balance between cerebral arterial inflow and venous outflow contributes to the maintenance of normal intracranial pressure, which depends not only on the arterial volume input and CSF volume but also on venous outflow.

The effect of intracranial fluid dynamics on intracranial pressure is a major component of the Monro-Kellie ${ }^{36,37}$ doctrine. As presented in Wilson's recent review, ${ }^{38}$ increasing evidence suggests that a venous pathology is central to the multiple conditions that cause a rise in intracranial pressure. A better understanding of the role of the venous system in neurocritical care is essential. In a prospective controlled study based on a grading system, Farb et $\mathrm{al}^{25}$ showed sinovenous stenosis in 27 of 29 patients with idiopathic intracranial hypertension and in only 4 of 59 control patients. Moreover, the severity of intracranial hypertension (which depends on the degree of venous congestion) was found to be closely related to the intradural sinus pressure. ${ }^{39}$ As the latter rises, slight parenchymal damage may progress to severe cerebral edema and/or hematoma if thrombolysis is delayed. Furthermore, some researchers have suggested that benign intracranial hypertension may be caused by venous hypertension, ${ }^{19,20}$ mostly due to stenosis or occlusions of the lateral sinuses. Moreover, it has been shown that dilation of one of the sinuses with a stent may reduce the pressure gradient and produce a striking reduction in symptoms. ${ }^{40}$ This venous sinus stent placement technique had a high technical success rate and was highly effective (80\%) in reducing the headache associated with benign intracranial hypertension. ${ }^{41}$ Nevertheless, sinus stenosis appears to result from elevated CSF pressure (rather than hypertension) in some cases. ${ }^{42}$

Also, there is some evidence that idiopathic intracranial hypertension may be characterized by elevated central venous pressure $^{20}$ in the absence of ventricular dilation, a mass lesion, or venous sinus thrombosis. ${ }^{43,44}$ Thus, it is possible that the cumulative effects of resistance to blood flow across the venous sinus pathways may lead to a substantial pressure increase in the intracranial drainage system. This question could be addressed (at least in part) by comparing venous sinus $\mathrm{Rd}$ measurements in patients versus healthy individuals. However, in the absence of such data, it seems premature to draw conclusions with regard to a possible causal link between venous sinus resistance to blood flow and intracranial hypertension.

The relationships between blood flow velocity, cross-sectional area, pressure drop, and resistance are very complex. A simplified relationship between fluid velocity and pressure can be described by the Bernoulli law, which is based on the fundamental physical law of energy conservation. The equation based on the Bernoulli law can take various forms, which differ in their complexity as a function of the type of fluid flow ${ }^{45}$ but can be represented as $(1 / 2) \cdot \rho \cdot V^{2}+P+\rho \cdot g \cdot z=$ Constant, where $\rho$ is the fluid attenuation, $V$ is the velocity, $P$ is the pressure, $z$ the vertical height relative to a reference location, and $g$ is the gravity constant. The first term of this equation accounts for the kinetic energy, and the 2 last terms represent the potential energy resulting from pressure and gravity. According to this principle, an increase in fluid velocity implies a concomitant decrease in pressure and vice versa. Therefore, if vessel resistance is increased by lumen constriction, the flow velocity rise would imply a decrease in pressure.

However, several assumptions must be made before applying the Bernoulli equation. In particular, the velocities must be uniformly distributed at the cross-sectional area, the fluid must be incompressible, and there must be no loss of energy. These assumptions tend to limit the applicability of the Bernoulli law to structures that are subject to deformation. Moreover, Cebral et $\mathrm{al}^{46}$ used phase-contrast MR imaging to investigate the flowarea relationship in the internal carotid and vertebral arteries. To the best of our knowledge, a similar study on the cerebral veins has not been performed. The pressure/area/flow relationships in compliant veins are much more complicated to evaluate than in the venous sinuses because the veins are prone to hydrostructural instability and are much more sensitive to slight pressure variations.

The present study had a number of limitations. First, the relatively small sample size must be taken into account when interpreting the results. A second limitation relates to the calculated $\mathrm{Rd}$ possibly being influenced by the hydrostatic pressure gradient across the venous sinus wall, which might influence the compliance of the vessels. Third, given that patterns of complex and disturbed flow may occur at branch points in the venous sinus network, the laminar flow required for the validity of the Poiseuille equation may not be met. It is also possible that the image quality was worsened by intravascular signal loss due to turbulence and intravoxel dephasing. ${ }^{47}$ Moreover, although the PCMRA technique may be useful for imaging slowing blood flow ${ }^{48}$ and can depict multidirectional flow (such as recirculating flow patterns) with good sensitivity, ${ }^{49}$ the choice of an optimal velocity-encoding value that enables avoiding velocity aliasing also constitutes a study limitation. ${ }^{26}$ Last, our data were collected from a group of young, healthy participants. Extending this investigation to more representative samples of older individuals (including patients with cerebrovascular/neurovascular disease) would be a valuable goal in the near future.

\section{CONCLUSIONS}

The results of this preliminary study suggest that PC-MRA can be used to quantify Rd in the venous sinus drainage system. These measurements may improve our understanding of certain cere- 
brovascular diseases. Along with flow measurements, this approach can also be used to calculate a pressure drop across vessel segments by application of the Poiseuille equation for laminar flow: pressure gradient $=$ resistance $\times$ flow.

\section{APPENDIX}

\section{Calculation of Overall Rd}

The overall Rd of the venous sinus system can be calculated by an analogy with an electric circuit (Fig 2). We have the following:

$$
\text { Overall } R d=\frac{R d S S S \times R d S t S}{R d S S S+R d S t S}+\frac{R_{\text {left side }} \times R_{\text {right side }}}{R_{\text {left side }}+R_{\text {right side }}} .
$$

Here, SSS and StS denote the superior sagittal sinus and the straight sinus, respectively, and $R_{\text {left side (or right side) }}$ represents the resistance of the left (or right) side of the venous sinus tree, calculated as the sum of the Rd of the 3-vessel segments (transverse sinus + sigmoid sinus + internal jugular vein):

$$
\begin{aligned}
\mathrm{R}_{\text {left } / \text { ight side }}=\mathrm{Rd} \text { Tranverse Sinus } & +\mathrm{Rd} \text { Sigmoid Sinus } \\
& +\mathrm{Rd} \text { Internal Jugular Vein. }
\end{aligned}
$$

\section{ACKNOWLEDGMENTS}

The authors are grateful to the staff members at the Institut Faire Faces (Amiens, France) for technical assistance and thank the study volunteers for their participation.

\section{REFERENCES}

1. Grand W, Hopkins LN. Vasculature of the Brain and Cranial Base: Variations in Clinical Anatomy. New York: Thieme; 1999

2. Stoquart-Elsankari S, Lehmann P, Villette A, et al. A phase-contrast MRI study of physiologic cerebral venous flow. J Cereb Blood Flow Metab 2009;29:1208-15 CrossRef Medline

3. Agnelli G, Verso M. Epidemiology of cerebral vein and sinus thrombosis. Front Neurol Neurosci 2008;23:16-22 CrossRef Medline

4. Dhungana S, Sharrack B, Woodroofe N. Idiopathic intracranial hypertension. Acta Neurol Scand 2010;121:71-82 CrossRef Medline

5. Bateman GA. Vascular hydraulics associated with idiopathic and secondary intracranial hypertension. AJNR Am J Neuroradiol 2002; 23:1180-86 Medline

6. Gross CE, Tranmer BI, Adey G, et al. Increased cerebral blood flow in idiopathic pseudotumour cerebri. Neurol Res 1990;12:226-30 CrossRef Medline

7. Greitz D, Hannerz J, Rähn T, et al. MR imaging of cerebrospinal fluid dynamics in health and disease: on the vascular pathogenesis of communicating hydrocephalus and benign intracranial hypertension. Acta Radiol 1994;35:204-11 CrossRef Medline

8. Kwon BJ, Han MH, Kang HS, et al. MR imaging findings of intracranial dural arteriovenous fistulas: relations with venous drainage patterns. AJNR Am J Neuroradiol 2005;26:2500-07 Medline

9. Sainte-Rose C, LaCombe J, Pierre-Kahn A, et al. Intracranial venous sinus hypertension: cause or consequence of hydrocephalus in infants? J Neurosurg 1984;60:727-36 CrossRef Medline

10. Shulman K, Ransohoff J. Sagittal sinus venous pressure in hydrocephalus. J Neurosurg 1965;23:169-73 CrossRef Medline

11. Zamboni P, Galeotti R, Menegatti E, et al. Chronic cerebrospinal venous insufficiency in patients with multiple sclerosis. J Neurol Neurosurg Psychiatry 2009;80:392-99 Medline

12. ElSankari S, Balédent $\mathrm{O}$, van Pesch V, et al. Concomitant analysis of arterial, venous, and CSF flows using phase-contrast MRI: a quantitative comparison between MS patients and healthy controls. J Cereb Blood Flow Metab 2013;33:1314-21 CrossRef Medline

13. Tsivgoulis G, Faissner S, Voumvourakis K, et al. "Liberation treatment" for chronic cerebrospinal venous insufficiency in multiple sclerosis: the truth will set you free. Brain Behav 2015;5:3-12 CrossRef Medline

14. Willems PW, Brouwer PA, Barfett JJ, et al. Detection and classification of cranial dural arteriovenous fistulas using 4D-CT angiography: initial experience. AJNR Am J Neuroradiol 2011;32: 49-53 CrossRef Medline

15. Leach JL, Jones BV, Tomsick TA, et al. Normal appearance of arachnoid granulations on contrast-enhanced CT and MR of the brain: differentiation from dural sinus disease. AJNR Am J Neuroradiol 1996;17:1523-32 Medline

16. Schoser BG, Riemenschneider N, Hansen HC. The impact of raised intracranial pressure on cerebral venous hemodynamics: a prospective venous transcranial Doppler ultrasonography study. J Neurosurg 1999;91:744-49 CrossRef Medline

17. Heiserman JE, Dean BL, Hodak JA, et al. Neurologic complications of cerebral angiography. AJNR Am J Neuroradiol 1994;15:1401-07; discussion 1408-11 Medline

18. Waugh JR, Sacharias N. Arteriographic complications in the DSA era. Radiology 1992;182:243-46 CrossRef Medline

19. King JO, Mitchell PJ, Thomson KR, et al. Cerebral venography and manometry in idiopathic intracranial hypertension. Neurology 1995;45:2224-28 CrossRef Medline

20. Karahalios DG, Rekate HL, Khayata MH, et al. Elevated intracranial venous pressure as a universal mechanism in pseudotumor cerebri of varying etiologies. Neurology 1996;46:198-202 CrossRef Medline

21. Dumoulin CL, Cline HE, Souza SP, et al. Three-dimensional timeof-flight magnetic resonance angiography using spin saturation. Magn Reson Med 1989;11:35-46 CrossRef Medline

22. Balédent O, Henry-Feugeas MC, Idy-Peretti I. Cerebrospinal fluid dynamics and relation with blood flow: a magnetic resonance study with semiautomated cerebrospinal fluid segmentation. Invest $R a$ diol 2001;36:368-77 CrossRef Medline

23. Elsankari S, Czosnyka M, Lehmann P, et al. Cerebral blood and CSF flow patterns in patients diagnosed for cerebral venous thrombosis: an observational study. J Clin Imaging Sci 2012;2:41 CrossRef Medline

24. Donnet A, Metellus P, Levrier O, et al. Endovascular treatment of idiopathic intracranial hypertension: clinical and radiologic outcome of 10 consecutive patients. Neurology 2008;70:641-47 CrossRef Medline

25. Farb RI, Vanek I, Scott JN, et al. Idiopathic intracranial hypertension: the prevalence and morphology of sinovenous stenosis. Neurology 2003;60:1418-24 CrossRef Medline

26. Fera F, Bono F, Messina D, et al. Comparison of different MR venography techniques for detecting transverse sinus stenosis in idiopathic intracranial hypertension. J Neurol 2005;252:1021-25 CrossRef Medline

27. Hatle L, Angelsen B. Doppler Ultrasound in Cardiology: Physical Principles and Clinical Applications. Philadelphia: Lea \& Febiger; 1982

28. Sundström P, Wåhlin A, Ambarki K, et al. Venous and cerebrospinal fluid flow in multiple sclerosis: a case-control study. Ann Neurol 2010;68:255-59 CrossRef Medline

29. Suzuki Y, Ikeda H, Shimadu M, et al. Variations of the basal vein: identification using three-dimensional CT angiography. AJNR Am J Neuroradiol 2001;22:670-76 Medline

30. Curé JK, Van Tassel P, Smith MT. Normal and variant anatomy of the dural venous sinuses. Semin Ultrasound CT MR 1994;15:499519 CrossRef Medline

31. Valdueza JM, von Münster T, Hoffman O, et al. Postural dependency of the cerebral venous outflow. Lancet 2000;355:200-01 CrossRef Medline

32. Lichtenstein D, Saïfi R, Augarde R, et al. The internal jugular veins are asymmetric: usefulness of ultrasound before catheterization. Intensive Care Med 2001;27:301-05 CrossRef Medline

33. Bateman GA. The reversibility of reduced cortical vein compliance in normal-pressure hydrocephalus following shunt insertion. $\mathrm{Neu}$ roradiology 2003;45:65-70 Medline

34. Bateman GA. Pulse-wave encephalopathy: a comparative study of 
the hydrodynamics of leukoaraiosis and normal-pressure hydrocephalus. Neuroradiology 2002;44:740 - 48 CrossRef Medline

35. Bateman GA. Vascular compliance in normal pressure hydrocephalus. AJNR Am J Neuroradiol 2000;21:1574-85 Medline

36. Kellie G. An account of the appearances observed in the dissection of two of the three individuals presumed to have perished in the storm of the $3 \mathrm{rd}$, and whose bodies were discovered in the vicinity of Leith on the morning of the 4 th November 1821 with some reflections on the pathology of the brain. Trans Med Chir Soc Edinb 1824;1:84-169

37. Monro A. Observations on Structure and Functions of the Nervous System. Edinburgh, UK: Creech and Johnson; 1783

38. Wilson MH. Monro-Kellie 2.0: the dynamic vascular and venous pathophysiological components of intracranial pressure. J Cereb Blood Flow Metab 2016;36:1338-50 CrossRef Medline

39. Tsai FY, Wang AM, Matovich VB, et al. MR staging of acute dural sinus thrombosis: correlation with venous pressure measurements and implications for treatment and prognosis. AJNR Am J Neuroradiol 1995;16:1021-29 Medline

40. Higgins JN, Owler BK, Cousins C, et al. Venous sinus stenting for refractory benign intracranial hypertension. Lancet 2002;359: 228-30 CrossRef Medline

41. Albuquerque FC, Dashti SR, Hu YC, et al. Intracranial venous sinus stenting for benign intracranial hypertension: clinical indications, technique, and preliminary results. World Neurosurg 2011;75:64852; discussion 592-95 CrossRef Medline

42. Higgins JNP, Pickard JD. Lateral sinus stenoses in idiopathic intracranial hypertension resolving after CSF diversion. Neurology 2004; 62:1907-08 CrossRef Medline

43. Friedman DI, Jacobson DM. Diagnostic criteria for idiopathic intracranial hypertension. Neurology 2002;59:1492-95 CrossRef Medline

44. Lee AG, Brazis PW. Magnetic resonance venography in idiopathic pseudotumor cerebri. J Neuroophthalmol 2000;20:12-13 CrossRef Medline

45. Fung Y. Biomechanics: Circulation. New York: Springer; 1997

46. Cebral JR, Castro MA, Putman CM, et al. Flow-area relationship in internal carotid and vertebral arteries. Physiol Meas 2008;29:585-94 CrossRef Medline

47. Ayanzen RH, Bird CR, Keller PJ, et al. Cerebral MR venography: normal anatomy and potential diagnostic pitfalls. AJNR Am J Neuroradiol 2000;21:74-78 Medline

48. Bono F, Lupo MR, Lavano A, et al. Cerebral MR venography of transverse sinuses in subjects with normal CSF pressure. Neurology 2003;61:1267-70 CrossRef Medline

49. Wheaton AJ, Miyazaki M. Non-contrast enhanced MR angiography: physical principles. J Magn Reson Imaging 2012;36:286-304 CrossRef Medline 